\title{
ANÁLISIS COMPARATIVO DE LAS REGLAS DE HAMBURGO Y LAS REGLAS DE RÓTTERDAM*
}

Ricardo SANDOVal LóPez ${ }^{* *}$

\section{INTRODUCCIÓN}

El Convenio de las Naciones Unidas sobre Transporte de Mercancías por Mar, conocido en la doctrina de los autores como las "Reglas de Hamburgo", fue aprobado con fecha 31 de marzo de 1978 por CNUDMI/UNCITRAL ${ }^{1}$, y por la Sexta Comisión de asuntos jurídicos de la Asamblea General de Naciones Unidas, en ese mismo año. Este instrumento jurídico entró en vigencia el 1 de noviembre de 1992, cuando se cumplió el número de 20 países que lo ratificaron.

En el caso de Chile, las Reglas de Hamburgo fueron ratificadas en el año 1982 y promulgadas como ley de la República, en virtud del Decreto Supremo $N^{\circ}$ 605, del Ministerio de Relaciones Exteriores, publicado en el Diario Oficial de fecha 12 de octubre de 1982. Más tarde, el contenido sustancial de este mismo instrumento fue incorporado en el Libro III del Código de Comercio de Chile, por la Ley № 18.680, de 11 de enero de 1988.

El Convenio de Naciones Unidas sobre el Contrato Internacional de Transporte de Mercancías total o parcialmente Marítimo, fue elaborado por el Grupo de Trabajo III Derecho del Transporte de la CNUDMI/UNCITRAL, por decisiones adoptadas en los $34^{\circ}$ y $35^{\circ}$ períodos de sesiones y aprobado por ella en su $41^{\circ}$ período de sesiones, en Nueva York, 2008. El Asamblea General de Naciones Unidas lo aprobó como Convenio de la organización mundial por Resolución $N^{\circ}$ 63/122 de 11 de diciembre de $2008^{2}$ y fue suscrito a invitación del Alcalde de la ciudad de Rótterdam, en una nave surta en ese puerto de los Países Bajos,

\footnotetext{
* Colaboración recibida el 16 de mayo y aprobada el 06 de junio de 2013.

** Doctor en Derecho, Profesor de Derecho Comercial, Universidad de Concepción y Universidad de Chile. Ex representante de Chile ante CNUDMI/UNCITRAL desde 1990 hasta 2011, participante en el Grupo de Trabajo III de la Comisión que elaboró el Convenio de Rótterdam y presidente de dicho organismo internacional por el período 2010-2011. Correo electrónico: risandov@udec.cl.
}

${ }^{1}$ Las siglas CDNUDMI/ UNCITRAL corresponden respectivamente a la denominación en idioma español e inglés a la Comisión de las Naciones Unidas para el Derecho Mercantil Internacional, principal órgano jurídico de Naciones Unidas.

${ }^{2}$ Véase A/RES 63/122 Asamblea General de Naciones Unidas. 
el 21 de septiembre de 2009, razón por la cual la doctrina de los autores lo denomina "Reglas de Rótterdam". En la actualidad ha sido suscrito por 24 países y ratificado por España y Togo, depositado que sea el vigésimo instrumento de ratificación el Convenio de Rótterdam, entrará en vigencia, los estados que lo ratifiquen deben denunciar las Reglas de La Haya-Visby y las Reglas de Hamburgo, a las cuales estén adscritos respectivamente, con lo cual se producirá la anhelada uniformidad de las normas internacionales sobre el transporte de mercancías, total o parcialmente marítimo.

\section{Contenido básico de las Reglas de Hamburgo}

Ellas se limitan a una breve regulación relativa a ciertos aspectos del contrato de transporte de mercancías por mar, pero no importan una normativa completa acerca de este contrato. El tema más relevante que constituye su contenido es el régimen de responsabilidad, donde se disciplina tanto la que corresponde al porteador como la del cargador marítimo. Este régimen de responsabilidad ha determinado que sólo hayan sido ratificadas por una treintena de países, entre ellos Chile por decisión del Gobierno Militar, la mayor parte de los Estados ratificantes, son países subdesarrollados y algunos mediterráneos.

Al igual que la mayoría de los instrumentos jurídicos de uniformidad del Derecho Mercantil Internacional, las Reglas de Hamburgo, en la parte primera, artículo 1, definen los conceptos de "porteador", "porteador efectivo", "cargador", "consignatario", "mercancías", "contrato de transporte marítimo", "conocimiento de embarque" y la frase "por escrito".

Todos estos conceptos deben ser entendidos en los términos precisos en los cuales han sido definidos en el Convenio, aunque los conceptos indicados no se caracterizan por ser descritos con amplitud ni flexibilidad.

\section{Definiciones de conceptos en las Reglas de Rótterdam}

Con el propósito recién señalado, el artículo 2 de este último texto uniforme define una mayor cantidad de conceptos, treinta en total, en forma más omnicomprensiva, acorde con el estado actual del progreso de la navegación, del transporte y del Derecho Marítimo, lo que facilita su aplicación y la determinación del sentido y alcance de sus disposiciones. Así, por ejemplo, la definición del contrato de transporte es más amplia que la contenida en las Reglas de Hamburgo, que sólo se aplica al transporte marítimo, en tanto que el concepto descrito en las Reglas de Rótterdam se aplica al contrato de transporte internacional de mercancías, total o parcialmente marítimo, incluyendo el desplazamiento por otras vías, siendo al menos una de ellas la marítima, lo que permite que la conducción se haga de "puerta a puerta" y no sólo de "puerto a puerto". 
En efecto, el artículo 1, Definiciones, de las Reglas de Rótterdam, dispone textualmente: "A los efectos del presente Convenio: 1. Por 'contrato de transporte' se entenderá todo contrato en virtud del cual el porteador se comprometa, a cambio del pago de un flete, a transportar mercaderías de un lugar a otro. Dicho contrato deberá prever el transporte marítimo de mercancías y podrá prever, además, su transporte por otros medios".

Destaca asimismo la definición de "parte ejecutante", contenida en el artículo 1 numero 6 letra a) del Convenio de Rótterdam, descrita como la persona que ejecute o se comprometa a ejecutar alguna de las obligaciones del porteador prevista en el contrato de transporte respecto de la recepción, la carga, la manipulación, la estiba, el transporte, el cuidado, la descarga o la entrega de las mercancías, en la medida que dicha persona actúe, directa o indirectamente, a instancias del porteador o bajo su supervisión o control. La responsabilidad del porteador se extiende así a toda persona que se comprometa o efectivamente ejecute alguna de las obligaciones del porteador. Esta noción, consustancial con el estado actual del transporte, no está definida en las Reglas de Hamburgo ni puede hacerse sinónima de la idea de porteador efectivo definida en este último Convenio.

El nuevo instrumento internacional, a diferencia de lo que ocurre con las Reglas de Hamburgo, define las nociones de "contrato de volumen", "transporte regular", "cargador documentario", "tenedor", "derecho de control", "parte controladora", "comunicación electrónica", "documento electrónico de transporte negociable", "documento electrónico de transporte no negociable", "transferencia de un documento electrónico negociable", etc., incorporando los avances tecnológicos tanto en el dominio de la navegación, del transporte en general y del derecho sobre la materia. Se advierte, en consecuencia, que las Reglas de Rótterdam disciplinan el transporte en relación con la realidad de nuestros días y no de acuerdo a la situación imperante en la década de los años 1970, como ocurre con las Reglas de Hamburgo.

\section{El Ámbito de aplicación en ambos Convenios}

El artículo 2 de las Reglas de Hamburgo y el artículo 979 del Código de Comercio de Chile, inspirado en ellas, disponen que las normas sobre el contrato de transporte de mercancías por mar, que ambos textos contienen, se aplicarán siempre que:

$1^{\circ}$ El puerto de carga o de descarga previsto en el contrato de transporte marítimo esté situado en territorio nacional, o

$2^{\circ} \mathrm{El}$ conocimiento de embarque $\mathrm{u}$ otro documento que haga prueba del contrato de transporte marítimo, estipule que el contrato se regirá por la disposiciones de este Código, o 
$3^{\circ}$ Uno de los puertos facultativos de descarga previstos en el contrato de transporte marítimo sea el puerto efectivo de la descarga y éste se encuentre dentro del territorio nacional.

Queda de manifiesto que tanto las disposiciones del Convenio de Hamburgo como las del Código de Comercio chileno, sólo se aplican al transporte marítimo de mercaderías, cumplidos que sean los presupuestos ya citados, excluyéndose, en consecuencia, su aplicación al transporte por cualquier otra vía distinta de la marítima.

En cambio, las Reglas de Rótterdam son aplicables respecto del contrato de transporte internacional de transporte de mercancías, háyase o no emitido conocimiento de embarque, total o parcialmente marítimo. Al ser así, el Convenio de Rótterdam se aplica también al Ilamado transporte multimodal, en el que el desplazamiento de las mercancías se hace, a lo menos, por dos vías diferentes. Esta modalidad de transporte tiene gran aplicación práctica en la actualidad, con el empleo de las unidades de carga y en especial del contenedor. De todas maneras, al igual que las Reglas de Hamburgo, en el Convenio de Rótterdam no se considera para su aplicación la nacionalidad de la nave, del porteador, de la parte ejecutante, del cargador, del consignatario o de cualquier otra persona interesada.

\section{Diferente realidad en la época de elaboración de ambos Convenios}

Las Reglas de Hamburgo son el reflejo de la realidad de la navegación, del transporte y del Derecho Marítimo de la época de su elaboración, esto es, en la década de 1970. En dicha época en el tráfico comercial marítimo existía una marcada distinción entre países porteadores y países cargadores, predominando el resguardo de los intereses de los países cargadores, en desmedro del relativo a los países porteadores, lo que se advierte claramente en el régimen de responsabilidad del porteador marítimo, lo que les ganó el desfavor de los países desarrollados, que permanecen hasta ahora en el régimen de las Reglas de La Haya-Visby.

Por el contrario, las Reglas de Rótterdam recogen el progreso tecnológico de la navegación y del transporte y los avances del Derecho Marítimo propios de la década de los años 2010, del siglo XXI, en que ellas fueron elaboradas. Siendo esto así, la diferencia entre países cargadores y países porteadores tiende paulatinamente a desaparecer, debido a que ciertas naciones que antes eran subdesarrolladas y, por ende, países cargadores, en la actualidad han emergido para convertirse en protagonistas de la economía mundial, como es el caso particular de Chile del sigo XXI.

Lo que acabamos sostener se confirma con la utilización masiva e irremplazable de ciertas unidades de carga, especialmente el contenedor, propia de la realidad del transporte comercial de fines del siglo XX y comienzos del 
siglo XXI, razón por la cual no aparece definida ni regulada en las Reglas de Hamburgo. En tanto, en las Reglas de Rótterdam se le define de la siguiente manera: "Artículo 1 Definiciones A los efectos del presente Convenio: 26. Por 'contenedor' se entenderá todo tipo de contenedor, plataforma o tanque portátil y cualquiera otra unidad de carga similar utilizada para agrupar mercancías, así como todo equipo auxiliar de dicha unidad se carga". Además, se hacen referencias frecuentes al contenedor a propósito de las obligaciones del porteador (art. 14), de los fundamentos de la responsabilidad (arts. 17 y 18), del transporte sobre cubierta (art. 25) y la obligación de entrega del cargador (art. 27.3), por mencionar sólo algunas.

En este mismo orden de ideas, es preciso destacar el empleo generalizado de las comunicaciones electrónicas en la negociación, formación y ejecución de los contratos internacionales ${ }^{3} y$, especialmente, en lo relativo a la expedición de los documentos propios del transporte ${ }^{4}$, en sus diversas modalidades de ejecución. Este fenómeno no estaba presente en la época de la elaboración y aprobación de las Reglas de Hamburgo. El nuevo instrumento jurídico del contrato de transporte internacional de mercancías, total o parcialmente marítimo, regula la emisión de documentos electrónicos de transporte, dejando subsistente la posibilidad de su creación en soporte de papel y, al mismo tiempo, disciplina la forma de circulación o transferencia de los documentos electrónicos de transporte negociables ${ }^{5}$. Además, se evita emplear la expresión "conocimiento de embarque", la que reemplaza por documento de transporte y documento electrónico de transporte, para incluir de esta manera todos los tipos de documentos empleados en el transporte (como, por ejemplo, sea waybills, way bills, straight bills).

\section{El CARÁCter DE LAS NORMAS DE AMBOS INSTRUMENTOS INTERNACIONALES}

Otro aspecto interesante de comparación entre las Reglas de Hamburgo y las Reglas de Rótterdam es el referente al carácter de sus normas, que en el caso del Convenio nombrado son de naturaleza predominantemente imperativas. Por el contrario, tratándose de las Reglas de Rótterdam, en ellas se logra un adecuado

\footnotetext{
${ }^{3}$ Véase nuestro artículo "Convención de Naciones Unidas sobre la utilización de las Comunicaciones Electrónicas en los Contratos Internacionales", Revista Chilena de Derecho Comercial, Año 1 № 1, pp. 59-80.

${ }^{4}$ Véase Ley Modelo de las Naciones Unidas sobre Comercio Electrónico de 1996, Ley Modelo de Naciones Unidas sobre Firma Electrónica de 2001 y el Convenio de las Naciones Unidas sobre la utilización de las Comunicaciones Electrónicas en los Contratos Internacionales de 2004 (en www. uncitral.org).

${ }^{5}$ Véase además: SANdoval López, Ricardo, "Derecho del Comercio Electrónico", Editorial Jurídica de Chile, 2004.
} 
equilibrio entre la naturaleza mandataria de la mayoría de sus normas, con la consagración de espacios adecuados para la autonomía de la voluntad, como ocurre en el caso del contrato de volumen. Recuérdese que el principio de la libertad contractual está recogido en casi todas las legislaciones del mundo y en textos uniformes como "Ios Principios de UNIDROIT sobre los Contratos Internacionales" ${ }^{\prime 6}$.

\section{Diferencias Relativas a los efectos Del CONTRATO DE tRANSPORTE}

No podemos pasar inadvertida la diferencia básica que existe entre las Reglas de Hamburgo y el Convenio de Rótterdam en lo que concierne la regulación de los efectos del contrato de transporte y, particularmente, en lo referente a las obligaciones del porteador y del cargador. Las Reglas de Hamburgo se limitan de definir el contrato de transporte de mercancías por mar o transporte marítimo, distinguiéndolo del contrato de fletamento, en sus diversas modalidades, teniendo en cuenta la naturaleza y la extensión de las obligaciones que asume el armador o naviero ${ }^{7}$, pero no regula en ninguna parte los derechos ni las obligaciones de las partes.

Por el contrario, las Reglas de Rótterdam, en los Capítulos 4 y 7 , disciplinan respectivamente y con detalles las obligaciones del porteador y las del cargador frente al porteador.

Haremos un breve análisis de estas obligaciones habida consideración que el porteador y el cargador son los elementos subjetivos más relevantes que participan en la relación de transporte y asumen en ella un rol protagónico. En lo que concierne a los deberes jurídicos del porteador, el Convenio de Rótterdam regula en el artículo 11 la obligación básica consistente en transportar las mercancías hasta el lugar de destino y entregarlas al destinatario, teniendo en cuenta que si bien es cierto se trata de una obligación de hacer, su ejecución no es personalísima en el contrato de transporte, toda vez que contempla la posibilidad de intervención de una parte ejecutante. Además, en el contexto de la clasificación de las obligaciones de hacer, en el que se distingue obligaciones de medios y de resultado, ésta se disciplina formando parte de esta última categoría, lo que hace riguroso el régimen de responsabilidad en caso de incumplimiento. Esta obligación tiene especial importancia respecto del período de responsabilidad, que se inicia en el momento en que el porteador o una parte ejecutante reciben las mercancías para su transporte y termina en el momento de la entrega de las mismas (art. 12 del Convenio de Rótterdam).

\footnotetext{
${ }^{6}$ Véase texto de los Principios de Unidroit en su última versión en www.unidroit.org.

${ }^{7}$ Esta distinción relativa a los contratos para la explotación comercial de las naves entre transporte marítimo y fletamento, fue hecha por el gran jusmercantilista francés René Rodière en una reforma del Derecho Marítimo de su país.
} 
Tratándose del detalle de las obligaciones del porteador, el Convenio de Rótterdam, en el artículo 13, párrafo 1, dispone que durante el período de responsabilidad previsto en su artículo anterior, éste está obligado a recibir, cargar, manipular, estibar, transportar, conservar, custodiar, descargar y entregar las mercancías con la diligencia y el cuidado debidos. Como complemento de las obligaciones ya descritas, el instrumento internacional suscrito en Rótterdam establece en su artículo 14 los deberes específicos que se imponen al porteador a propósito del viaje, en que debe actuar con la debida diligencia antes, al comienzo y durante el viaje por mar para:

a) poner y mantener la nave en adecuado estado de navegabilidad;

b) tripular, armar y avituallar debidamente la nave y mantenerla así tripulada, armada y avituallada durante todo el viaje;

c) mantener las bodegas y demás partes del buque donde se transporten las mercancías y todo contenedor por él suministrado y en cuyo interior o sobre el cual se transporten mercancías, en el estado adecuado para su recepción, transporte y conservación.

Como si esta regulación fuese poca, las Reglas de Rótterdam contienen asimismo en sus artículos 14 y 15 normas relativas a las mercancías que pueden constituir peligro y sobre el sacrificio de las mismas durante el viaje por mar.

En el Capítulo 7 de las Reglas de Rótterdam, bajo el epígrafe "Obligaciones del cargador frente al porteador", artículo 27, se establece que el primero nombrado debe entregar las mercancías preparadas para su transporte, acondicionadas de manera que puedan resistir el transporte previsto, incluidas las operaciones de carga, estiba, sujeción y descarga y que no causen daño alguno a las personas o bienes. Habida consideración de los avances tecnológicos en materia de transporte se dispone además que cuando un contenedor o un vehículo de transporte por carretera o ferroviario sea llenado por el cargador, éste debe estibar, sujetar y anclar el contenido en el contenedor o vehículo, o sobre él, con la diligencia y el cuidado debidos.

A mayor abundamiento, el Convenio de Rótterdam disciplina también la cooperación mutua entre el porteador y el cargador en cuanto al intercambio de información e instrucciones, imponiendo asimismo al cargador de manera específica el deber de facilitar información, dar instrucciones y proporcionar documentos para el transporte de las mercancías.

\section{DiverSO RÉGIMEN DE RESPONSABILIDAD DEL PORTEADOR}

Sin duda que el aspecto comparativo más relevante entre los dos Convenios Internacionales, es el relativo al régimen de responsabilidad del porteador y del cargador, en el transporte internacional de mercancías. 
En el caso de las Reglas de Hamburgo, según su artículo 4일 la responsabilidad del porteador se basa en el principio según el cual éste responde de la pérdida, del daño o del retraso que sufran las mercancías durante todo el período en que ellas se encuentran bajo su custodia, sea en tierra o durante su transporte. Se trata de una responsabilidad que no está fundada en la culpa del porteador, sino en una presunción, simplemente legal, según la cual si el hecho que origina la pérdida, el daño o el retraso se produce durante el período de custodia, éste está obligado a responder, a menos que enerve esta presunción probando que él, sus dependientes o agentes adoptaron todas las medidas que razonablemente podían exigirse para evitar el hecho y sus consecuencias. El Convenio de Hamburgo contiene también normas diferentes sobre limitación de la responsabilidad del porteador marítimo, para los casos pérdida o avería y retraso en la entrega de las mercancías, que se complementan con una regla de excepción, según la cual éste no puede invocar el beneficio de dicha limitación. Este régimen de responsabilidad del porteador marítimo se incorporó en el Libro III del Código de Comercio de Chile en virtud de la Ley № 18.680 de 1988.

Los artículos 12, período de responsabilidad, 17, fundamento de la responsabilidad y 59, límites de responsabilidad, de las Reglas de Rótterdam, fueron los que suscitaron los debates más profundos y las discusiones mas vehementes en el seno del Grupo de Trabajo III Derecho del Transporte durante su elaboración.

El Convenio de Rótterdam mantuvo el fundamento de la responsabilidad del porteador basado en el período de custodia, recogiendo también las tres causas básicas de responsabilidad: la pérdida, el daño o el retraso en la entrega de las mercancías. En efecto, el artículo 12 del instrumento internacional recién aludido dispone: "1. El período de responsabilidad del porteador por las mercancías establecido en el presente Convenio comienza en el momento en que el porteador o una parte ejecutante reciba las mercancías para su transporte y termina en el momento de su entrega". En el párrafo 2 del mismo artículo se regulan los aspectos especiales relativos tanto a la recepción como a la entrega de las mercancías, en las diversas situaciones que pueden presentarse al respecto.

Sin embargo, a diferencia de las Reglas de Hamburgo, el nuevo instrumento internacional suscrito en Rótterdam, dispone que el reclamante tiene el deber de probar que la pérdida, el daño o el retraso o el hecho o circunstancia que contribuyó a causarlo, se produjo durante el período de custodia. El peso de la prueba inicial, esto es, de la existencia de la pérdida, daño o retraso y del momento en que se produjo, recae ahora sobre el cargador, tal como es el caso en las Reglas de La Haya-Visby.

Al ser así, pareciera que el nuevo Convenio estaría imponiendo un peso de la prueba superior al que está previsto en las Reglas de Hamburgo. Empero, ello no es de esa manera, porque para demostrar que la pérdida, el daño o retraso 
se produjeron durante el período de custodia o período de responsabilidad del porteador, al cargador le basta con probar que las mercancías fueron entregadas en buen estado al porteador y que el consignatario no las recibió o las recibió con averías o en retardo. El supuesto básico del Convenio de Rótterdam es que no pueden existir daños sin que se pueda explicar su causa y si la causa resulta inexplicada o inexplicable, la responsabilidad recae automáticamente sobre el porteador ${ }^{8}$.

\section{Causas de EXONERACIÓN DE RESPONSABILIDAD DEL PORTEADOR}

En esta materia es donde se aprecia la diferencia más notable entre el régimen de responsabilidad del porteador previsto en el Convenio de Hamburgo y el establecido en las Reglas de Rótterdam.

En efecto, en las Reglas de Hamburgo el porteador puede exonerarse de responsabilidad probando que él, sus dependientes o agentes adoptaron todas las medidas que razonablemente podían exigirse para evitar el hecho y sus consecuencias, enervando la presunción de que la pérdida, el daño o el retraso se produjo durante el período de custodia. Aun cuando en la normativa de Hamburgo se omite mencionar quién debe rendir la prueba que los daños se produjeron durante el período de custodia del porteador, la interpretación preponderante de la jurisprudencia en esta materia ha sido en el sentido de que el cargador debe probar la pérdida, avería o retraso, de acuerdo al principio general según el cual la prueba de los hechos incumbe a quien los alega.

Por otra parte, el Convenio de Hamburgo no establece la obligación del porteador de poner la nave en condiciones de navegabilidad, ni contempla un vínculo entre el incumplimiento de esta obligación y el derecho del cargador a ser indemnizado por la pérdida o daño de la carga.

Tratándose de las Reglas de Rótterdam, según el párrafo 2 del artículo 17, el porteador queda exonerado total o parcialmente si prueba que la causa o una de las causas de la pérdida, el daño o el retraso no le es imputable a él ni a cualquier parte ejecutante, ni al capitán, o a algún miembro de la tripulación, ni a los empleados del porteador o de una parte ejecutante, ni a ninguna otra persona que ejecute o se comprometa a ejecutar alguna de las obligaciones del porteador con arreglo al contrato de transporte, en la medida en que dicha persona actúe, directa o indirectamente, a instancias del porteador o bajo su supervisión o control.

\footnotetext{
${ }^{8}$ Véase el documento de Naciones Unidas A/CN.9/544, párrafo 90: "Se apoyó firmemente la opinión de que la naturaleza de la responsabilidad en el proyecto del artículo 17 debía basarse en la presunción de falta (...) El Grupo de Trabajo hizo suyo en general el criterio de que el porteador debería ser responsable de las pérdidas no explicadas que se produjeran durante su período de responsabilidad, pero que dicho porteador debería tener la oportunidad de demostrar posteriormente la causa del daño".
} 
La segunda posibilidad de exonerarse de responsabilidad que tiene el porteador, que constituye una alternativa respecto de la prueba general de la falta de culpa, está representada por una lista de causales específicas de exoneración que se enumeran en el párrafo 3 del artículo 17 del nuevo Convenio. Entre estas causales de exoneración del porteador se encuentran: la fuerza mayor, riesgos, peligros y accidentes del mar o de otras aguas navegables, guerra, hostilidades, conflicto armado, piratería, terrorismo, motines y tumultos, por nombrar sólo algunas. Con todo, el Convenio de Rótterdam no mantuvo las exoneraciones basadas en la innavegabilidad del buque ni en la culpa náutica. La primera quedó eliminada al establecer este nuevo instrumento internacional la obligación continua del porteador de mantener la navegabilidad de la nave y la segunda fue excluida tras un intenso debate donde se recordó que históricamente ella se había prestado para abusos de parte de los armadores. Las exoneraciones de responsabilidad no son absolutas pues sólo tienen el carácter de presunciones de inocencia, porque no liberan automáticamente al porteador, sino una vez acreditada la relación de causalidad entre el hecho y el daño. Aquí se invierte el peso de la prueba que volvería a recaer sobre el reclamante. En consecuencia, no obstante la prueba de una causa de exoneración, la responsabilidad del porteador se mantiene:

a) si el reclamante prueba que la culpa del porteador o de alguna de las persona que actúan por él según el artículo 18 causó o contribuyó a causar el hecho o la circunstancia que el porteador alega en su descargo, y

b) si el reclamante prueba que un hecho o circunstancia no enumerado en el párrafo 3 del artículo 17 contribuyó a causar la pérdida, el daño o el retraso y el porteador no puede probar que ese hecho o circunstancia no le es imputable a él ni a ninguna de las personas que actúan por él, según el artículo 18 del mismo texto uniforme.

Por otra parte, en conformidad con lo previsto en el artículo 17, párrafo 5 del Convenio de Rótterdam, la responsabilidad del porteador también subsiste, por la totalidad o parte de la pérdida, el daño o el retraso:

a) si el reclamante prueba que la pérdida, el daño o el retraso fue o es probable que haya sido total o parcialmente causado por el estado de innavegabilidad de la nave, deficiencias de armamento, de avituallamiento o de la tripulación de la nave, o el hecho de que las bodegas u otras partes de la nave donde su transporten las mercancías, incluido todo contenedor suministrado por el porteador y sobre el cual o en cuyo interior se transporten las mercancías, no estuviesen en condiciones debidas para recibirlas, transportarlas y conservarlas, y

b) si el porteador no puede probar: i) que ninguno de los hechos o circunstancias mencionadas en el apartado a) del párrafo 5 de este artículo causó la pérdida, el daño o el retraso, o ii) que cumplió con su obligación de obrar con la debida diligencia conforme a lo establecido en el artículo 14 del mismo Convenio. 
La redacción del párrafo 5 del artículo 17 de las Reglas de Rótterdam es clara en cuanto a no exigir del reclamante una prueba definitiva de la innavegabilidad de la nave, prueba esta que podría ser de suyo extremadamente difícil de rendir, cuando no imposible hacerlo, por falta de conocimiento directo de las circunstancias bajo las cuales se produjo la pérdida, el daño o el retraso durante el período de custodia del porteador. De acuerdo al nuevo convenio, bastaría con que el reclamante acredite cierta relación o nexo entre las malas condiciones de navegabilidad alegadas y el daño que sufrió la mercancía.

En el evento en que porteador quede exonerado parcialmente de responsabilidad, en virtud del artículo 17, párrafo 6 del Convenio de Rótterdam, tiene que responder únicamente de la parte de la pérdida, el daño o el retraso que sea imputable al hecho o circunstancia del cual sea responsable. Se aprecia en general que las normas relativas a exoneración del porteador contenidas en el Reglas de Rótterdam son más completas, detalladas y minuciosas que las establecidas por las Reglas de Hamburgo y por las Reglas de La Haya-Visby, instrumentos internacionales ambos en actual vigencia, sobre todo en lo concerniente al peso de la prueba.

Cuando el Convenio de Rótterdam entre en vigencia, lo que ocurrirá mas temprano que tarde, en la práctica el asunto de los daños sufridos por la carga se resolverá mediante un proceso que, fundamentalmente, podría comprender cuatro diferentes etapas, a saber:

a) En la primera etapa se exigirá que el demandante establezca el fundamento presuntivo del libelo acreditando que la carga sufrió daños durante el período de responsabilidad del porteador. En esta misma etapa el demandante no tendría que probar la causa del daño y, de no rendirse ninguna otra prueba, el porteador sería responsable de toda pérdida inexplicada que se produjera durante su período de responsabilidad;

b) En la segunda etapa, el porteador tendría que refutar la presunción del demandante demostrando que se debe a una de las causales de exoneración previstas en el nuevo convenio y que ese peligro fue la causa de la pérdida, daño o retraso sufrido por la carga;

c) En la tercera etapa el demandante tendría la oportunidad de probar que "el peligro exceptuado" no fue la única causa de los daños y que el porteador ha contribuido en parte a ellos al no cumplir su obligación de velar debidamente por la carga;

d) La cuarta etapa tendría lugar una vez que se haya demostrado por el reclamante que el daño tenía múltiples causas, oportunidad en la que se dividirá la responsabilidad por los daños entre las diferentes causas que los originaron, según lo previsto en el artículo 17, párrafo 6 del nuevo convenio. En este aspecto las Reglas de Rótterdam siguen el principio ya consagrado en las Reglas de Hamburgo, según el cual en caso de concurrencia de causas que produzcan 
la pérdida, el daño o el retraso, el porteador responde solamente de la parte de la pérdida, daño o retraso que es imputable al hecho o circunstancia del cual él es responsable. A diferencia de las Reglas de Hamburgo, el Convenio de Rótterdam no impone expresamente el peso de la prueba al porteador acerca de la extensión de la pérdida o del daño del cual es responsable.

En fin, en las Reglas de Rótterdam se establecen reglas sobre la responsabilidad solidaria del porteador y una o más partes ejecutantes marítimas, por la pérdida, el daño o el retraso ${ }^{9}$ en la entrega de las mercancías. Se define además el concepto de retraso y se establecen normas acerca del cálculo de la indemnización y el aviso que debe darse en caso de ocurrir uno cualquiera de los hechos de los cuales deriva la responsabilidad del porteador.

\section{LIMITACIÓN DE LA RESPONSABILIDAD DEL PORTEADOR}

El Convenio de Hamburgo establece en su artículo 6 que la responsabilidad del porteador por los perjuicios resultantes de la pérdida o el daño de la mercancía, está limitada a la suma equivalente a 835 unidades de cuenta por bulto u otra unidad de carga transportada, o a 2,5 unidades de cuenta por kilogramo de peso bruto de las mercancías perdidas o dañadas, si esta cantidad fuere mayor. La responsabilidad del porteador por retraso en la entrega está limitada a una suma equivalente a dos veces y media el flete que deba pagarse por las mercancías que hayan sufrido retraso, pero no excederá la cuantía total del flete que deba pagarse en virtud del contrato de transporte marítimo de mercancías.

Asimismo, en las Reglas de Hamburgo se establece que la responsabilidad acumulada por pérdida o daño y retraso no puede exceder de las 835 unidades de cuenta por bulto u otra unidad de carga transportada, o de 2,5 unidades de cuenta por kilogramo de peso bruto de la mercadería perdida, dañada o retrasada, si esta cantidad es mayor.

En el Convenio de Rótterdam, los límites de responsabilidad del porteador subieron a la suma equivalente a 875 unidades de cuenta por bulto u otra unidad de carga transportada o a 3 unidades de cuenta por kilogramos de peso bruto de la mercancía perdida o dañada, si esta cantidad fuere mayor.

\section{RESPONSABILIDAD DEL CARGADOR}

Finalmente, en cuanto a la responsabilidad de cargador, el artículo 12 de la Reglas de Hamburgo dispone que este no será responsable de la pérdida sufrida

\footnotetext{
${ }^{9}$ Durante el debate sobre el concepto de retraso y el cálculo de la indemnización, hicimos presente en el Grupo de Trabajo III, que para Chile y los países del hemisferio sur, era muy importante evitar el retraso o indemnizarlo cuando ocurriera, porque en el caso especial de la exportación de frutas y hortalizas contamos con la ventaja de la diferencia de estaciones del año, llegando con esos bienes al hemisferio norte cuando en este no se pueden producir.
} 
por el porteador o por el porteador efectivo, ni del daño por el buque, a no ser que tal pérdida o daño hayan sido causados por culpa o negligencia del cargador, sus empleados o agentes. Los empleados o agentes del cargador tampoco serán responsables de la pérdida o daño, a no ser que hayan sido causados por culpa o negligencia de su parte.

En cambio, las Reglas de Rótterdam, en su artículo 30, disponen que el cargador responde de la pérdida o el daño causado al porteador, siempre que este último pruebe que dicha pérdida o daño fue causado por incumplimiento de parte del cargador de las obligaciones que le impone el Convenio. El principio en que se basa la responsabilidad del cargador es, en el hecho, el mismo que se aplica al porteador, en cuanto que el sujeto que invoca la responsabilidad, en este caso, el porteador, debe probar que la pérdida o el daño se produjo por el incumplimiento de las obligaciones del cargador.

\section{CONCLUSIÓN}

Chile desde 1991 ha aplicado las Reglas de Hamburgo que fueron incorporadas en el Libro III del Código de Comercio, en virtud de la Ley № 18.680, de 1988. Sin embargo, tanto la ratificación como la incorporación del Convenio de Hamburgo de 1978 se hizo en una época en que no existía un gobierno democrático, ni siquiera funcionaba el Congreso Nacional, que debió haber deliberado acerca de tal ratificación.

En alguna medida esta ratificación se justificaba en la época en que se dio, porque Chile era a la sazón fundamentalmente un país exportador de productos.

En la actualidad, nuestro país tiene una economía emergente, ha celebrado convenios internacionales de libre comercio con muchos países, lo que le permite tener a su disposición el mercado de casi todo el mundo, por lo que realiza transporte internacional gracias a grandes flotas navieras, habiendo dejado ya su condición de simple país cargador. Al ser de esta manera, un gran sector del tráfico mercantil está a favor de suscribir y ratificar las Reglas de Rótterdam, sin desconocer que algunos sectores interesados en la defensa de los intereses de la carga, están aún reticentes a dicha suscripción y posterior ratificación.

Con todo, la corriente mayoritaria es la que aboga por que Chile abandone el criterio nacionalista de mantener la vigencia de las Reglas de Hamburgo, y que incorpore en el grupo de países que quieren que mediante las Reglas de Rótterdam se logre la deseada uniformidad de las normas que regulan el contrato de transporte internacional de mercancías, total o parcialmente marítimo. 